\title{
ESTIMATION OF ABOVEGROUND BIOMASS USING LANDSAT-5/TM AND NOAA/AVHRR
}

\author{
Muneharu Sato", Etsuji Ishiguro", Shinsuke Fujita*, Koichi Hirata ${ }^{* *}$ and Takakazu Miyahara ${ }^{* * *}$ \\ (*Faculty of Agriculture, Kagoshima University, Kagoshima 890, Japan) \\ (**PASCO Ltd., Meguro, Tokyo 153, Japan) \\ (***ELM Ltd., Kaseda, Kagoshima 899-52, Japan)
}

\begin{abstract}
The methodology of biomass estimation of forest areas in Japan has heavily depended on the mesh method. The method, however, demands a large amount of time-consuming labor to attain a reliable accuracy. Therefore, we have been working on the use of satellite data to assess the biomass as one of the alternatives to the conventional method.

As the first step in our research, we put our efforts into identifying specific objects on the ground and into evaluating their quantities. So far we have succeeded in estimating crop yield and volcanic ash deposits from the satellite data. They are, however, at level ground showing rather small variations in spectral reflectance.

The next step is to clarify the topographic effects on the biomass estimation of mountainous areas. Since the system to receive and analyze NOAA/AVHRR data was installed at United Graduate School of Agricultural Sciences, Kagoshima University in 1995, attempts have been made to use their data for those purpose.

NOAA data have been conventionally used to study surface properties not requiring high resolution because of their low resolutions, $1.1 \mathrm{~km}$ at best. The satellites, however, can supply the data four times a day. Therefore, in this study, some attempts were made to use NOAA data efficiently to estimate the biomass of the mountainous forest areas in Japan. The results suggest that the data supplied by NOAA can be used to estimate biomass of the forest areas with sufficient reliability.
\end{abstract}

Key words: NOAA, Landsat, Biomass, Index, forest.

\section{Introduction}

Satellite remote sensing techniques have been used to assess various environmental elements and their changes. The prediction of rice yield, the estimation of the amount of volcanic ash deposits and the evaluation of the degree of damage by a natural disaster have been successfully achieved by using Landsat-5 and MOS-1 data (Ishiguro et al., 1991, Ishiguro et al.,1994, Ishiguro et al.,1995, Namba et al.,1995 and Sato,1996). These satellites, however, supply their data only once in 17 days (Table 1). Also it should be a day with a clear sky to collect a good data on the target ground surface. This property of these satellites hinders the research efficiency severely especially in the southern part of Japan where the annual precipitation amounts to over $2,000 \mathrm{~mm}$.

NOAA, on the other hand, provides us with data four times a day since the signals of the two satellites can be received in Kagoshima. Their resolutions are, however, low, $1,100 m \times 1,100 m$ at their best (Table 1.). In 1995, the NOAA/AVHRR receiver with its analyzer, jointly developed by ELM Ltd. and us, was installed at United Graduate School of Agricultural Sciences, Kagoshima University. This enables us to access the data every day. Therefore, in this project, the object was determined to evaluate the effectiveness of the use of NOAA as a substitute or compensation for other satellites. And, as an example, the biomass of a forest plot was estimated.

The biomass of a forest has been estimated by the mesh method that depends on a series 
of cumbersome ground surveys in meshed square plots of $100 \mathrm{~m} \times 100 \mathrm{~m}$ each. This method demands a large amount of labor but does not necessarily yield accurate results (Yoshida and Kobayashi, 1989). In this study, the data surveyed by the mesh method and by NOAA on Takakuma Experimetal Forest, Kagoshima University were compared to assess the validity of the NOAA data to estimate biomass.

Table 1. The properties of NOAA/A VHIRR and Landsat-5/TM

\begin{tabular}{|c|c|c|c|c|c|}
\hline Satellite & Band & Spectrum & IFOV & Swath Width & Orbital Element \\
\hline NOAA & 1 & $0.58 \sim 0.68 \mu \mathrm{m}$ & \multirow{5}{*}{$1.1 \mathrm{~km}$} & \multirow{5}{*}{$2,700 \mathrm{~km}$} & altitude: \\
\hline (Advanced & 2 & $0.725 \sim 1.10$ & & & $833 \mathrm{~km}$ \\
\hline very high & 3 & $3.55 \sim 3.93$ & & & or $870 \mathrm{~km}$ \\
\hline resolution & 4 & $10.30 \sim 11.30$ & & & recurrent: \\
\hline radiometer ) & 5 & $11.50 \sim 12.50$ & & & 12 hours \\
\hline Landsat & 1 & $0.45 \sim 0.52 \mu \mathrm{m}$ & \multirow{6}{*}{$30 m$} & \multirow{7}{*}{$185 \mathrm{~km}$} & altitude: \\
\hline ( Thematic & 2 & $0.52 \sim 0.63$ & & & $915 \mathrm{~km}$ \\
\hline \multirow[t]{5}{*}{ mapper ) } & 3 & $0.63 \sim 0.69$ & & & \\
\hline & 4 & $0.75 \sim 0.90$ & & & recurrent: \\
\hline & 5 & $1.55 \sim 1.75$ & & & 17 days \\
\hline & \multirow[t]{2}{*}{6} & $2.08 \sim 2.35$ & & & \\
\hline & & $(10.40 \sim 12.5$ & $120 m)$ & & \\
\hline
\end{tabular}

\section{Materials and Methods}

The data from the

Takakuma Experimental Forest, Kagoshima University scanned by NOAA and Landsat- 5 were subjected to analyses. The area of the forest is about 3,000ha and was divided into 37 survey plots as shown in Fig.1. Since we had a database on each plot for its vegetation as well as its area, its biomass was calculated for this study as the reference.

First, NDVIs ( Normalized Differential Vegetation Index ) obtained by

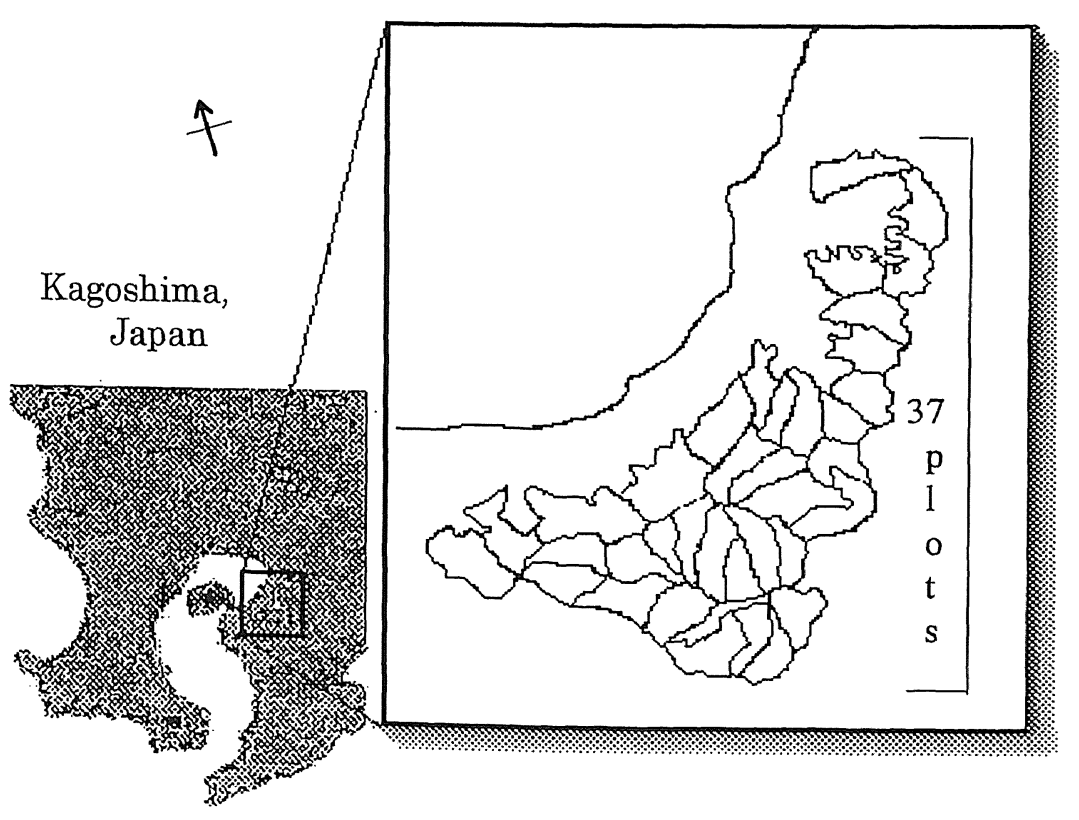
Landsat data based on Fig.1 The location of the Takakuma Experimental Forest.
surveys of March 10,1989,

November 21,1989, December 10,1990 and March 2, 1993 were correlated with the biomass estimates based on the data base as a reference. Then NDVIs for NOAA data collected on November 11,1995, January 5,1996, February 28,1996, April 7,1996 and May 13, 1996 were found and also compared with the biomass estimates. Incidentally for Landsat-5, Band-3 and 
Band-4 and for NOAA/AVHRR, Band-1 and Band-2 correspond to red and infrared wave lengths, respectively.

Then attempts were made to find a way to overcome the disadvantages of NOAA's resolution. By applying various model-selection methods (Snedecor and Cochran,1967, Allen, 1971), it was found that models using Band-2 (wave length 0.725 0.68 $\mu \mathrm{m}$ ) and Band-3 $(3.55 \sim 3.93 \mu \mathrm{m})$ estimate biomass better than those with other bands. It was also noted that the non-linearity of the response of each band has its own characteristics. Taking these facts into consideration, the following three models were applied:

\begin{tabular}{|c|c|c|c|c|c|}
\hline Model 1: & biomass $=\beta_{0}+$ & $\beta_{1} \mathrm{~B}_{2}+$ & $\beta_{2} \mathrm{~B}_{3}+$ & $\beta_{3}\left(1 / B_{2}\right)+$ & $\beta_{4}\left(1 / \mathrm{B}_{3}\right)$ \\
\hline Model 2: & biomass $=\beta_{0}+$ & $\beta_{1} \mathrm{~B}_{2}+$ & $\beta_{2} \mathrm{~B}_{3}+$ & $\beta_{3}\left(B_{2}\right)^{1 / 2}+$ & $\beta_{4}\left(\mathrm{~B}_{3}\right)^{1 / 2}$ \\
\hline Model 3: & biomass $=\beta_{0}+$ & $\beta_{1} \mathrm{~B}_{2}+$ & $\beta_{2} \mathrm{~B}_{3}+$ & $\beta_{3} \log _{e}\left(B_{2}\right)+$ & $\beta_{4} \log _{e}\left(B_{3}\right)$, \\
\hline
\end{tabular}

\section{Results and Discussion}

The correlation coefficient between NDVI and the biomass of each forest block was low regardless of the type of satellite $(r=0.0 \sim 0.29)$. The estimates based on NOAA were, as expected, less reliable than those based on Landsat. Since it has been known that NDVI changes from season to season (Kawamura and Edamatsu, 1993), it may lead to erroneous results if NDVI is used to estimate biomass at specific times without any adjustment.

As the next step, the models proposed in this study were applied only to NOAA data since the object of this study is focused on better use of the NOAA data. All of them proved to be practical and reliable. For example, the actual models fitted to the data of May 13,1996 by a regression method were as follows:

$$
\begin{aligned}
& \text { Model 1: biomass }=-3109.73+23.88 \mathrm{~B}_{2}-4.86 \mathrm{~B}_{3}+759346.05 / \mathrm{B}_{2}-143407.76 / \mathrm{B}_{3}, \\
& \text { Model 2: biomass }=6089.58+93.29 \mathrm{~B}_{2}-19.60 \mathrm{~B}_{3}-2492.69\left(\mathrm{~B}_{2}\right)^{1 / 2}+915\left(\mathrm{~B}_{3}\right)^{1 / 2} \\
& \text { Model 3: biomass }=7022.21+47.03 \mathrm{~B}_{2}-9.77 \mathrm{~B}_{3}-8390.62 \log _{\mathrm{e}}\left(\mathrm{B}_{2}\right)+5323.24 \log _{\mathrm{e}}\left(\mathrm{B}_{3}\right) .
\end{aligned}
$$

Their correlation coefficients are $0.528,0.531$, and 0.530 , respectively.

Since these models are designed to fit the biomasses of target plots in the particular experimental forest, the coefficients would differ from place to place. But it is not difficult to estimate the parameters by a rather small scale field survey. It would be also true that so long as the vegetation and geographic features are similar, the parameters would be applicable to other places. Further, with the increase of the data, the model can be improved just as other statistics oriented models.

\section{Conclusion}

This study proved that the use of NOAA data can compensate the field work and save labor costs. Since the data obtained by NOAA have a low resolution, it is not good to apply the conventional indices directly. Therefore, it is necessary to develop new models that utilize information without any loss. Our approach has shown one of the alternatives to the conventional methodologies. By refining our models from a theoretical point-of-view, it would be possible to increase the reliability since the models found were mainly derived 
statistically.

\section{Acknowledgments}

The authors would like to acknowledge the continuing efforts of Mr. Sumitaka Kashiwagi and Mr. Hideo Ikeda for storing the data of NOAA on MOs. We also would like to thank Dr. Masamichi Chyo for providing data on the Takakuma Experimental Forest and Mr. Kaoru Hyodo for contributing his skill in preparing this paper.

\section{References}

Allen, D., M., 1971: Mean square error of prediction as a criteria for selecting variables. Technometrics, 13, 469-475.

Ishiguro, E., Mishra, K.K., Hidaka, Y. and Miyazato, M., 1991: A study on the effects of Mt.Sakurajima's falling ash over crop and forest area using image processing for LANDSAT-5, MOS-1 and JAFSA digital data. Proc. $5^{\text {th }}$ International ColloquiumPhysical Measurements and Signature in Remote Sensing, France, 509-512.

Ishiguro, E., Ogawa, Y., Miyazato, M. and Chen, J.Y., 1994: Discrimination of the forest damaged tea fields using Landsat-5/TM data. Bull.Fac.Agric.Kagoshima Univ., 44, $35-41$.

Ishiguro, E. Iwasaki, K. and Morita, K., 1995: Identifying a damaged forest area using Landsat-5/TM data--- Damaged area with typhoon 9119 around Hita city. J. of Japanese Society of Agricultural Machinery, 57, 65-73.

Kawamura, K. and Edamatsu, Y., 1993: Seasonal variations of the vegetation index of the rice field and forest in the Tohoku Area of Japan. Proc. of the IGARSS '93, Tokyo, 3, $1143-1145$.

Namba, N., Ishiguro, E., Cho, K., Wakamatsu and Miwa, K. 1995:Identification of areas damaged by localized heavy rain using satellite data and aerial color photographs. Trans of JSIDRE, 177, 1-8.

Sato, M., Ishiguro, E., Iwasaki, K., Kanemasu, E.T., Flitcroft, I.D., Mishra, K.K., Hirata, K. and Masumizu, T. 1995: Estimating volcanic ash deposits and their effetcs on leaf optical properties using satellite data. Proc. Int. Colloq. Photosynthesis and Remote Sensing, August 1995, Montpellier (France), 451-456.

Snedecor, G. W. and Cochran, W. G., 1967: Multiple regression. In Statistical methods (6 $^{\text {th }}$ edition), Iowa State University Press, Ames, 381-418.

Yoshida, S. and Kobayashi, T., 1989: Information system of forest in Takakuma Experimental Forest. Bull. Kagoshima Univ. Forest, 17, 37-109. 